\title{
Arazi toplulaştırma projelerinde parsel şekil değişiminin nicel değerlendirmesi: Konya ili Çumra ilçesi Abditolu mahallesi örneği
}

\author{
Quantification of changes in the shape of parcels in land consolidation: example from \\ Abditolu district of Çumra town of Konya province
}

\author{
Ela ERTUNÇ*1,a \\ ${ }^{1}$ Konya Teknik Üniversitesi, Mühendislik ve Doğa Bilimleri Fakültesi, Harita Mühendisliği Bölümü, 42250, Konya
}

• Geliş tarihi / Received: 19.02.2020 • Düzeltilerek geliş tarihi / Received in revised form: 17.10.2020 • Kabul tarihi / Accepted: 07.11.2020

\begin{abstract}
Öz
Arazi toplulaştırması (AT) dağınık ve parçalı parselleri bir araya getirerek, parsel şekillerini iyileştiren, arazi sahipleri için sulama, drenaj ve yol hizmetlerinin geliştirilmesini sağlayan projelerdir. Mevcut parsel şekillerinin iyileştirilmesi, arazi toplulaştırma projelerinin en önemli faydalarından biridir. Arazi toplulaştırma projesi öncesi ve sonrası mevcut parsellerin şekillerindeki değiş̧imini belirleyen birçok indeks vardır. Bunlar, Şekil İndeksi (SI), Fraktal Büyüklük İndeksi (FD), Alan Şekil Faktörü (AFF), Şekil Faktörü (FORM), Alan Çevre Oranı (APR), Kare Piksel Ölçeği (SqP) ve Compactness İndeks (Icmp)'dir. Bu indeksler parsel şekillerinin modern tarım için uygunluğunu nicel olarak ölçmek amacıyla literatürde kullanılmaktadır. Bu çalışmada Konya ili Çumra ilçesi Abditolu Mahallesi arazi toplulaştırma projesi verileri kullanılarak arazi toplulaştırması öncesi ve sonrası parsel şekil değişimleri incelenmiştir. Bunun içinde şekil indeks göstergelerinden SI, FD, AFF, FORM, APR, SqP ve Icmp kullanılmıştır. Çalışmanın sonucunda; AT öncesi ortalama FD, SI, AFF, FORM, SqP, APR ve Icmp değerleri sirayla 1.3579, 1.8486, 0.0424, 0.5334, - $0.7819,6.5530$ ve 0.5334; AT sonrası ise $1.3084,1.3912,0.0465,0.5848,-0.8478,4.9320$ ve 0.5848 olarak hesaplanmıştır. Elde edilen sonuçlara göre AT öncesi ve sonrasında parsel şekillerinde genel olarak iyileşme olduğu görülmüştür. FD, SI, FORM, Icmp indeksleri AT öncesi ve sonrası parsel şekil değişimini daha iyi yansıtmıştır.
\end{abstract}

Anahtar kelimeler: Arazi toplulaştırma, Coğrafi bilgi sistemi (CBS), Parsel şekil indeksi

\begin{abstract}
Land consolidation $(L C)$ are projects that combine scattered and fragmented parcels, improving parcel shapes, and enabling the development of irrigation, drainage and road services for landowners. Improving existing parcel shapes is one of the most important benefits of Land Consolidation projects. There are many indexes that determine the parcel shape change before and after land consolidation. These are Shape Index (SI), Fractal Size Index (FD), Area Shape Factor (AFF), Shape Factor (FORM), Area Perimeter Ratio (APR), Square Pixel Scale (SqP) and Compactness Index (Icmp). These indexes are used in the literature to quantitatively measure the suitability of parcel shapes for modern agriculture. In this study, parcel shape changes pre-consolidation and post-consolidation have investigated by using the data of Abditolu land consolidation project in Çumra district of Konya. Therefore, SI, FD, AFF, FORM, APR, SqP and Icmp, which are among the shape index indicators, have used. As a result of the study; FD, SI, AFF, FORM, SqP, APR and Icmp average values before LC are 1.3579, 1.8486, 0.0424, 0.5334, -0.7819, 6.5530 and 0.5334, respectively; after the $L C$, it has calculated as $1.3084,1.3912,0.0465,0.5848,-0.8478,4.9320$ and 0.5848 . According to the results, there has a general improvement in parcel shapes before and after the LC. FD, SI, FORM, Icmp indexes better reflected parcel shape change before and after $L C$.
\end{abstract}

Keywords: Land consolidation, Geographical information system (GIS), Parcel shape index

*a Ela ERTUNÇ; eertunc@ktun.edu.tr, Tel: (332) 20518 85, orcid.org/0000-0002-6982-0459 


\section{Giriş}

Günümüzde dünya nüfusu hızla artarken, toprak ve su gibi sınırlı doğal kaynakların önemi de giderek arttırmaktadır. Nüfusun hızla artması ile birlikte, artan nüfusun gıda ihtiyacı ve güvenliği bu alanda yapılacak yatırım ve desteklemelerle mümkündür. Sürdürülebilir gıda güvenliği için de tarımsal araziler üzerindeki etkinliğin sağlanması gerekmektedir. Mevcut tarımın sorunlarından biri arazi parçalanmasıdır ve arazi parçalanması arazi kullanımı ve tarımsal verimlilik üzerinde zararlı bir etkisi vardır (Jurgenson, 2016; Boonchom vd., 2017; Munnangi vd., 2020). Çünkü parçalanmış arazilerin şekilleri küçük ve bozuk olmakta ve bu da çiftçinin üretim süresini arttırmakta (sürüm, ekim, ilaçlama, gübreleme, hasat vb.), arazinin değerini etkilemekte, modern tarım yöntemlerinin uygulanmasını zorlaştırmakta, işçilik ve üretim maliyetini artırmaktadır. Tarımsal yapının iyileştirilmesi ve arazi parçalanmasını önlemek için alınabilecek en iyi önlem Arazi Toplulaştırmasıdır (AT). Arazi Toplulaştırması (Pašakarnis ve Maliene, 2010), tarımsal verimliliği arttırarak kırsal alanların sürdürülebilir kalkınmasını (FAO, 2003) hedefleyen çok amaçlı bir arazi yönetimi ve planlama yaklaşımıdır. Çin, Hindistan, Nepal, Özbekistan ve Japonya gibi Asya ülkeleri tarımsal verimliliği artırmak ve kırsal altyapıyı iyileştirmek için arazi toplulaştırma projeleri yapmaktadırlar (Wu vd., 2005; Djanibekov vd., 2012; Li vd., 2018). Bu projeler, ekili alanların miktarını ve kalitesini iyileştirmek, arazi parçalanmasını azaltmak (Ertunç,2020), arazi mülkiyet yapısını düzenlemek, modern tarımsal kalkınmayı artırmak, kırsal çevreyi güzelleştirmek, kırsal kalkınma ve yoksulluğun azaltılmasını desteklemek için kullanılan bir araç haline gelmiştir (Jiang vd., 2017; Song ve Pijanowski, 2014; Zhou vd., 2019; 2020).

Arazi toplulaştırması dağınık ve parçalı parselleri bir araya getirerek, parsel şekillerini iyileştiren, arazi sahipleri için sulama, drenaj ve yol hizmetlerinin geliştirilmesini sağlayan projelerdir. Arazi toplulaştırma projelerinden beklenen faydaların kapsamlı bir şekilde değerlendirilmesi gerekmektedir.

Arazi toplulaştırma projeleri parsel şekillerinin iyileştirilerek modern tarım tekniklerinin uygulanmasına imkân vermektedir. Makul en/boy oranına sahip dörtgen parsellerde yapılan tarımsal işlemler, mekanizasyon verimliliği açısından daha başarılı olduğundan, şekilsiz ve parçalı parseller kısa sürede yeniden düzenlenerek tarıma kazandırılmalıdır. Bundan dolayı parsel şekillerinin tarımsal üretim üzerinde büyük oranda etkisi olduğundan arazi toplulaştırma projesi uygulanmadan önce ve sonra parsel şekillerinin incelenmesi önemli bir değerlendirmedir. Parsel şekillerinin incelenmesinde parselin düzgün bir geometrik yapıya ne derece sahip olduğu araştırılır. Birçok araştırmacı Arazi toplulaştırma projelerinde parsel şekil değişimini incelemek amaciyla indeksler geliştirmiştir. McGarigal vd., (1995), parsel şeklini metrik olarak değerlendirmek amaciyla parsel şekil indeksi geliştirmiştir. Frohn (1998) parsel şeklini kara piksel adını verdiği indeks ile ölçmüştür. Husar (2000) tarafından da parsel şeklini incelemek için Compactnes indeksi geliştirilmiştir. Russ (2002) parsel şeklini şekil faktörü adını verdiği yöntem ile hesaplamıştır. Gonzalez vd., (2004) parsel şekil değişimini belirlemek için alan şekil faktörü ve alan çevre oranını kullanmışlardır. Demetriou vd,. (2013) parsel şekil değişiminin analizinde parsel kenar uzunluğu, parsel sınırları ve açısını dikkate alarak ağırlıklı parametrelerden oluşan parsel şekil indeksini (PSI) geliştirmişlerdir. $\mathrm{Bu}$ şekil indeksleri literatürde yaygın kullanıma sahiptir ve bu alanda birçok çalışma yapılmıştır. Kirmikil ve Oksanen (2013)'de yaptığı çalışmada tarımsal araziler için şekil tanımlayıcı indeksler geliştirmiştir ve çalışmasında Compactness indeksi kullanmıştır. Kirmikil ve Arıcı (2013), seçtikleri dört farklı uygulama alanında kadastro durumunda ve toplulaştırma sonrası parsel şekil değişimini belirlemek için Şekil İndeksi ve Fraktal Büyüklük indeksini kullanmışlardır. Gasiorowski ve Bielecka (2014), Polonya da yaptıkları uygulamada parsel şekillerini değerlendirmek için şekil indeksini kullanmışlardır. Bayram ve Değirmenci (2018)'de Niğde ilinde yapılan bir arazi toplulaştırma projesi verilerini kullanarak toplulaştırma öncesinde ve sonrasında parsel şekillerindeki değişiklikleri şekil indeksi, şekil faktörü, kare piksel ölçeği ve fraktal büyüklük indeksini kullanarak incelemişlerdir. Değirmenci vd., (2019) çalışmalarında Şanlıurfa Bozca arazi toplulaştırma projesi sonrasında yine önceki durumu da dikkate alarak şekil faktörü (FORM), şekil indeksi (SI), Fraktal büyüklük indeksi (FD), alan çevre oranı (APR) ve kare piksel ölçeği (SqP) indekslerini kullanarak parsel şekillerindeki değişimi incelemişlerdir. Geısse ve Hudeco Vá (2019), compactness indeksi kullanarak AT öncesi ve sonrasi parsellerin şekil değişimini incelemişlerdir. Cebeci (2019)'da yaptığı çalışmada, Burdur Yeşilova Sazak köyü arazi toplulaştırma projesini, şekil indeksi, fraktal boyut, ortalama şekil indeksi, alan ağırlıklı ortalama şekil indeksi ve çift logaritmalı fraktal boyut indeksi kullanarak incelemiştir. 
$\mathrm{Bu}$ çalışmanın amacı, Konya ili Çumra ilçesi Abditolu Arazi toplulaştırma projesi verilerini kullanarak toplulaştırmadan önce ve sonra parsel şekil değişimlerini SI, FD, AFF, FORM, APR, SqP ve Icmp indeksleri kullanarak incelemek ve bu indekslerin hem birbirleriyle tutarlılığını hem de arazi toplulaştırma projelerinde kullanılabilirliğini araştırmaktır.

\section{Materyal ve metot}

\subsection{Materyal}

Karasal iklimin egemen olduğu Konya ili Çumra ilçesi Abditolu Mahallesi araştırma alanı olarak seçilmiştir. Abditolu, Konya iline $50 \mathrm{~km}$, Çumra ilçesine $24 \mathrm{~km}$ uzaklıktadır. Çalışma alanı haritası Şekil 1'de verilmiştir. Bölgenin ekonomisi tarım ve hayvancılığa dayalıdır.

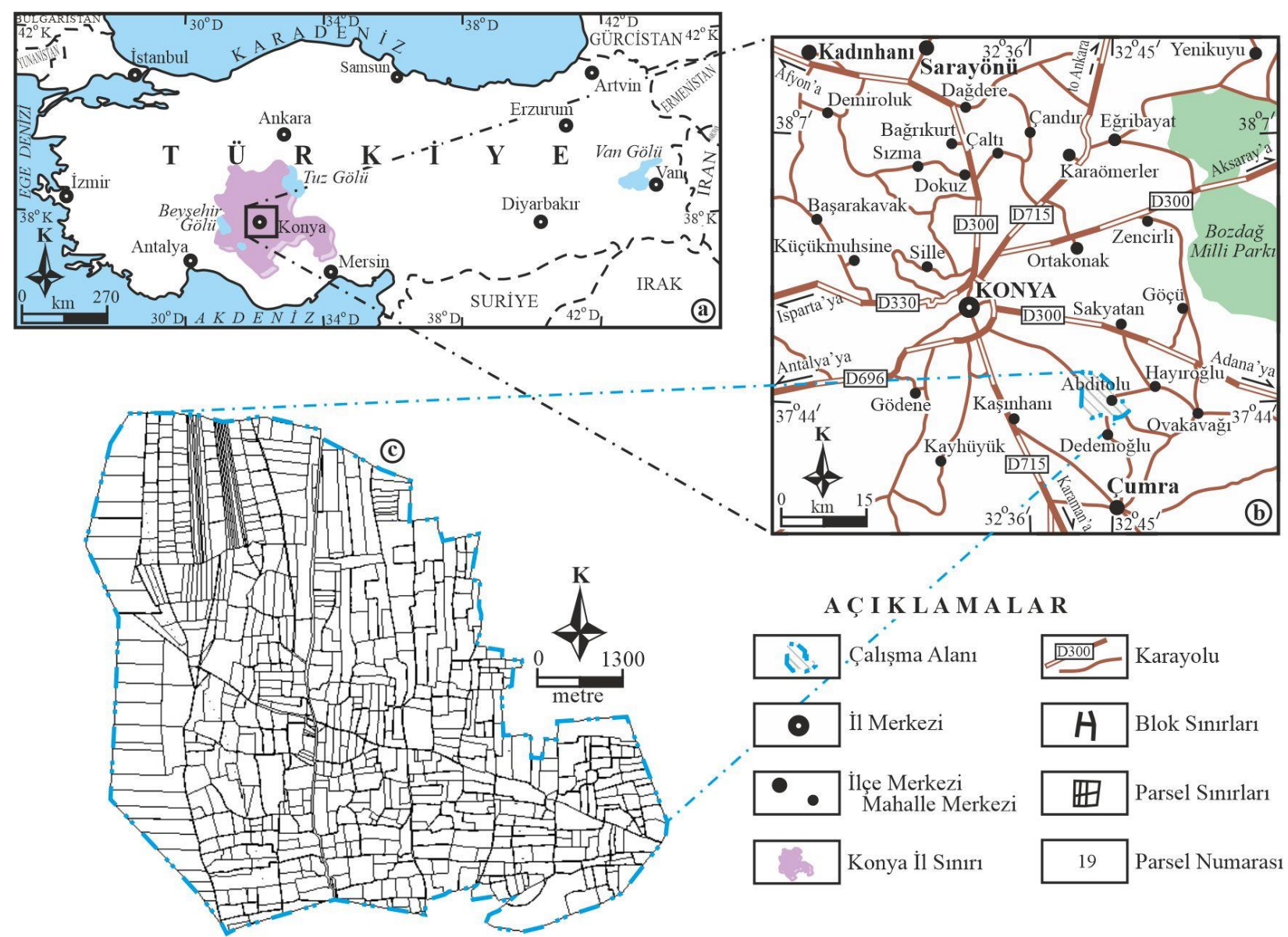

Şekil 1. (a) ve (b) Çalışma alanının lokasyon haritası. (c) Çalışma alanının kadastro durum haritası

\subsection{Metot}

Çalışmada şekil indeks göstergelerini tematik haritalar ile göstermek için ArcMAP 10.5 ve NetCAD 5.0 yazılımları kullanılmıştır.

\section{Fraktal Büyüklük Indeksi (FD)}

Parsel şekillerini oransal olarak tanımlamak için kullanılan indekslerden biri Fraktal Büyüklük indeksidir (1). (1) numaralı formülde, PÇ, her bir parselin çevresini, PA'da her bir parselin alanını ifade eder. $\mathrm{Bu}$ oran 1 ve 2 arasinda değerler almaktadır. Sonuçta 1'e yakın değerler kare gibi düzgün şekilleri ifade ederken, 2'ye yakın değerler düzgün olmayan şekilleri ifade etmektedir (Akkaya Aslan vd., 2007; Arslan vd., 2017).

$F D=\frac{2 \ln (\mathrm{PC})}{\ln (\mathrm{PA})}$

\section{Şekil İndeksi (SI)}

Şekil indeksi (2) arazi toplulaştırma projelerinde parsellerin şekillerini değerlendirmek amacıyla kullanılmaktadır (McGarigal vd., 1995). Her bir parselin çevresi (PÇ) ve alanı (PA) olmak üzere şekil indeksi;

$S I=\frac{\mathrm{PC}}{\sqrt{2 \pi \mathrm{PA}}}$ 
Eşitliği ile hesaplanmaktadır. SI değerinin oldukça küçük olması parsel şekillerinin düzgün geometrik şekillere yakın olduğunu göstermektedir. $\mathrm{Bu}$ değerin büyümesi parsel şekillerinin düzgün geometrik şekillerden uzaklaştığ 1 anlamına gelmektedir (Değirmenci vd., 2017).

\section{Alan şekil faktörü (AFF)}

Alan Şekil faktörü (AFF) (3) eşitliği ile gösterilir.

$A F F=\frac{\mathrm{PA}}{\mathrm{PC}^{2}}$

Eşitlikteki PA: parselin alanı, PÇ ise parselin çevresini ifade etmektedir (Değirmenci vd., 2019).

Şekil faktörü (FORM)

Şekil faktörü (4) ise:

$F O R M=\frac{4 \pi \mathrm{PA}}{\mathrm{PC}^{2}}$ ile hesaplanır (Russ, 2002).

Kare piksel ölçeği (SqP)

Kare piksel ölçeği (5):

$S q P=\frac{1-4 \sqrt{\mathrm{PA}}}{\mathrm{PC}}$

Eşitliği ile hesaplanır (Değirmenci ve vd., 2019). Eşitlikte PA: parselin alanı, PÇ: parselin çevresini ifade etmektedir.

Alan çevre oranı (APR)

Alan çevre oranı (6):

$A P R=\frac{\mathrm{PC}}{\sqrt{\mathrm{PA}}}$

Eşitliği ile hesaplanır (Gonzalez vd., 2004)

\section{Compactness indeks (Icmp)}

Metrik olarak, bir parselin şekli, Husár (2000) tarafindan geliştirilen ve aşağıdaki gibi hesaplanan Compactness indeksi (7) kullanılarak ifade edilir (Geisse ve Hudecová, 2019).

$\mathrm{Icmp}=\frac{4 \pi \mathrm{PA}}{P C^{2}}$

PA: parselin alanı, PÇ: da parselin çevresini ifade etmektedir.

\section{Bulgular ve tartışma}

Abditolu Mahallesi proje verileri Tarım Reformu Genel Müdürlüğü'nden temin edilmiştir. Çalışma alanına ait bilgiler Tablo 1'de verilmiştir.

Tablo 1. Abditolu Mahallesi proje özet tablosu

\begin{tabular}{|c|c|c|}
\hline \multicolumn{3}{|c|}{ Proje Özet Tablosu } \\
\hline & AT Öncesi & AT Sonrası \\
\hline Toplam Proje Alanı (ha) & 2532.40 & 2491.19 \\
\hline Toplam Parsel Sayıs1 & 690 & 441 \\
\hline İşletme Sayısı & 394 & 394 \\
\hline $\begin{array}{l}\text { Ortalama İşletme } \\
\text { Büyüklügü (ha) }\end{array}$ & 6.48 & 6.32 \\
\hline $\begin{array}{l}\text { Ortalama Parsel Alanı } \\
\text { (ha) }\end{array}$ & 3.67 & 5.65 \\
\hline
\end{tabular}

AT öncesi ortalama parsel alanı 3.67 (ha)'dan 5.65 ha' a çıkmıştır (Tablo 1). Uygulama alanında toplulaştırma oranı \%36.09'dur. Proje sahasından parseller ortalama büyüklügüü ülke ortalaması olan 15 dekarın altında olduğu görülmektedir. Proje sahasında 77 büyük alanlı Tarım Reformu Genel Müdürlüğü tarafindan dağıttılan araziler mevcuttur. $\mathrm{Bu}$ araziler ortalama parsel büyüklügünü artırmaktadır.

Tablo 2'de görüldüğü gibi AT öncesi proje alanındaki parsellerin \%17,83'ü 10 dekar altındadır. 11-100 dekar arasındaki parseller \%75,94 oranındadır. Parsellerin 93 tanesi hisseli durumdadır. AT sonrası durum incelendiğinde ise, 10 dekarın altındaki parsel sayısında azalma mevcuttur. Toplulaştırmanın mantığına uygun olarak parsel büyüklükleri artmıştır. 100 dekarın üzerindeki parsel sayısında artış görülmektedir.

Abditolu Arazi Toplulaştırma öncesi ve sonrası şekil değişimini belirlemede kullanılan göstergelerin temel tanımlayıcı istatistiksel sonuçları Tablo 3'te verilmiştir. Tablo 3 de'de görüldüğü gibi medyan değerlerinin AT öncesi ve sonrası birbirine yakın olmasını verilerin benzer istatistiksel dağılıma sahip olduğunu göstermektedir. İndekslerin ortalama değerlerine baktığımızda FD, SI, FORM ve Icmp indeksleri arazi toplulaştırma sonrasında parsel şekil değişimini daha iyi yansıtmaktadır. Demetriou vd. (2013) yaptıkları çalışmada FD, SI ve FORM indekslerinin tutarlı indeksler olmadığı sonucuna ulaşmışlardır. Fakat bu uygulama alanı için bu indeks değerlerinin kullanımı uygundur. 
Tablo 2. Uygulama alanındaki parsellerin toplulaştırma öncesi ve sonrası büyüklük ve dağılış oranları

\begin{tabular}{cccc}
\hline \multicolumn{2}{c}{ Arazi Toplulaştırma Öncesi } & \multicolumn{2}{c}{ Arazi Toplulaştırma Sonrası } \\
\hline Parsel Grupları (da) & Parsel Sayısı & Parsel Grupları (da) & Parsel Sayısı \\
\hline $0-5$ & 77 & $0-5$ & 59 \\
$6-10$ & 46 & $6-10$ & 25 \\
$11-20$ & 133 & $11-20$ & 58 \\
$21-50$ & 295 & $21-50$ & 134 \\
$51-100$ & 96 & $51-100$ & 82 \\
$101-500$ & 42 & $101-500$ & 83 \\
$501-1000$ & 1 & $501-1000$ & 0 \\
$1000>$ & 0 & $1000>$ & 0 \\
\hline Toplam & $\mathbf{6 9 0}$ & Toplam & $\mathbf{4 4 1}$ \\
\hline
\end{tabular}

Tablo 3. Tanımlayıcı temel istatistik sonuçları

\begin{tabular}{lllllll} 
İndeksler & Minumum & Maximum & Ortalama & $\begin{array}{l}\text { Stand. } \\
\text { Sapma }\end{array}$ & Varyans & Medyan \\
\hline FD önce & 1.1271 & 1.9062 & 1.3579 & 0.1589 & 0.0252 & 1.2971 \\
FD sonra & 1.2157 & 1.5815 & 1.3084 & 0.4170 & 0.1739 & 1.2760 \\
SI önce & 1.0397 & 13.4900 & 1.8486 & 1.5125 & 2.2877 & 1.2943 \\
SI sonra & 1.1128 & 4.1379 & 1.3912 & 0.3774 & 0.1425 & 1.2372 \\
AFF önce & 0.0004 & 0.2501 & 0.0424 & 0.0295 & 0.0009 & 0.0475 \\
AFF sonra & 0.0004 & 0.0642 & 0.0465 & 0.0147 & 0.0002 & 0.0520 \\
FORM önce & 0.0055 & 0.9251 & 0.5334 & 0.3713 & 0.1378 & 0.5968 \\
FORM sonra & 0.0584 & 0.8075 & 0.5848 & 0.1849 & 0.0342 & 0.6532 \\
SqP önce & -1.0400 & -0.0834 & -0.7819 & 0.2556 & 0.0653 & -0.8712 \\
SqP sonra & -1.0131 & -0.2722 & -0.8478 & 0.1526 & 0.0233 & -0.9108 \\
APR önce & 1.9994 & 47.8209 & 6.5530 & 5.3617 & 28.7479 & 4.5883 \\
APR sonra & 3.9449 & 14.6686 & 4.9320 & 1.3381 & 1.7904 & 4.3859 \\
Icmp önce & 0.0054 & 0.6202 & 0.5334 & 0.3713 & 0.1379 & 0.5969 \\
Icmp sonra & 0.0584 & 0.8075 & 0.5848 & 0.1849 & 0.0342 & 0.6532
\end{tabular}

Arazi Toplulaştırma öncesi ve sonrası Fraktal Büyüklük indeks değerlerindeki değişim Şekil 2'de görülmektedir.
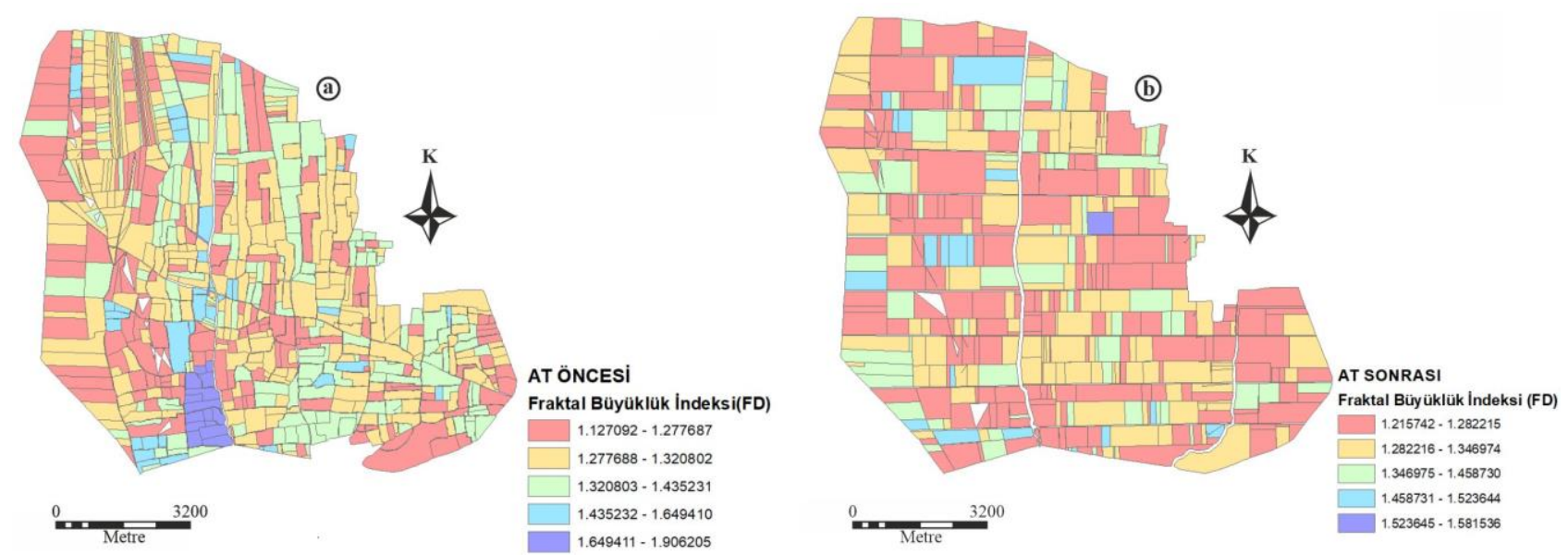

Şekil 2. Fraktal Büyüklük İndeksi (FD) haritası. (a) Arazi toplulaştırma öncesi. (b) Arazi toplulaştırma sonrası 
AT öncesinde Fraktal büyüklük indeksi 1.1271 ile 1.9062, AT sonrası ise 1.2157 ile 1.5825 değerleri arasındadır. Fraktal Büyüklük değeri ortalamaları ise AT öncesinde 1.3579 iken, AT sonrasinda 1.3084 olmuştur. Değirmenci vd., (2019)'da Şanlıurfa Bozca Köyü arazi toplulaştırma projesi yapılmadan önce FD indeks değerini 1.23 ile 1.52, AT sonrasinda 1.18 ile 3.28 arasinda hesaplamışlardır. Parsel şeklini ölçen FD indeksi 1 ila 2 arasında değerler olabilir. Bu değerlerin 1'e yaklaşması parsel şekillerinin düzgün geometrik olduğunu, 2'ye yaklaşması şekilsiz geometrik şekiller olduğunu ifade etmektedir. Şekil 2'de AT sonrasında FD değerleri 1'e yaklaştığ görülmektedir. FD değerinin 1'e yaklaşmış olması kare gibi düzgün şekilli parsel sayısının arttığını, parsel şekillerinin iyileştiğini göstermektedir.

Parsel şekil değişiminin incelenmesi amacıyla kullanılan bir diğer indeks de Şekil İndeksidir (SI).
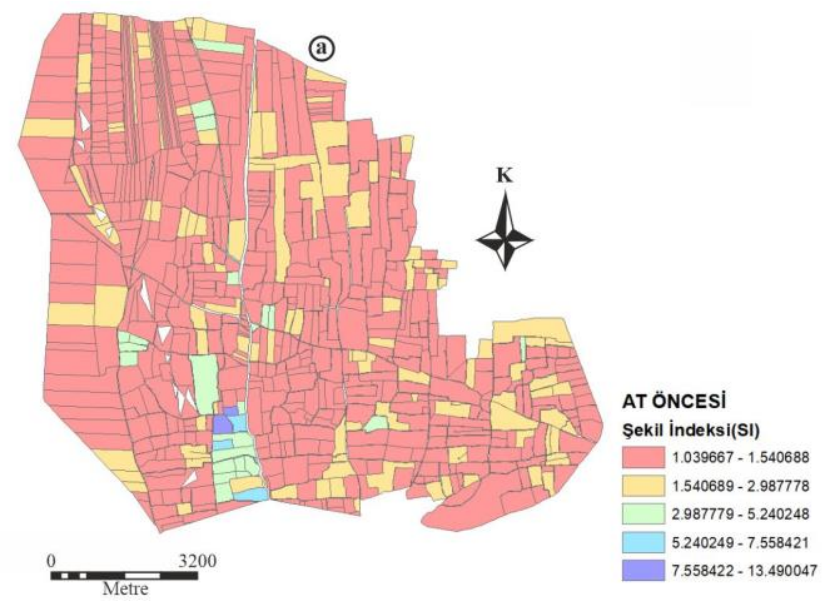

$\mathrm{Bu}$ indeks değeri $1 \leq \mathrm{SI} \leq \infty$ aralığında değerler almaktadır. $\mathrm{Bu}$ indeks değerinin 1'e yaklaşması parsellerin kare şeklinde olmasını, 1'den uzaklaşması parsellerin düzensiz şekillere sahip olduğunu ifade etmektedir. Parsellerin en/boy oranının büyüdükçe SI değeri 1'den uzaklaşır ve parsellerin düzensiz şekillere sahip olduğunu gösterir. AT öncesi ve sonrası Şekil İndeks değerlerindeki değişim Şekil 3'te görülmektedir. Parsel AT öncesinde SI değeri 1.0396 ile 13.4900, AT sonrasinda ise 1.1128 ile 4.1379 arasinda değişmiştir. SI değerlerinin ortalaması AT öncesinde $1.8486 \mathrm{iken,} \mathrm{bu} \mathrm{oran} \mathrm{AT} \mathrm{sonrasinda}$ 1.3912 olmuştur. Salvati (2014) tarafindan yapılan çalışmada parsel şekil indeksini 1949 yılında 1.32 ve 2008 y1lında 1,70 olarak belirlemiştir. Arslan vd., (2017) çalışmasında SI değerlerini 1.21-1.58 aralığında hesaplanmıştır. Şekil 3 'te AT öncesi ve sonrasında parsel şekil indeksi değerlerinde iyileşme olmuştur.

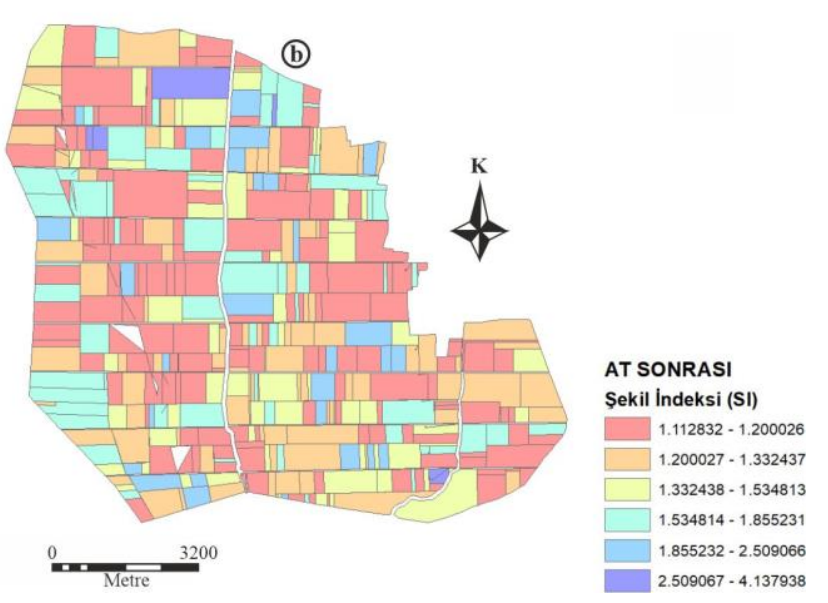

Şekil 3. Şekil İndeksi (SI) haritası. (a) Arazi toplulaştırma öncesi. (b) Arazi toplulaştırma sonrası

Parsellerin arazi toplulaştırma öncesi ve sonrasında AFF indeksine göre değişimi Şekil 4'teki gibidir. AT öncesi Alan Şekil Faktörü (AFF) değerleri 0.0004 ile 0.2501 , AT sonrasinda 0.0046 ile 0.064 arasında değişmektedir. AFF değerleri ortalaması ise AT öncesinde 0.0424 iken, AT sonrasinda 0.0465 olmuştur. Gonzalez vd. (2004) yaptıkları çalışmada Alan Şekil Faktörüne göre 36 parsel şekli tanımlamışlardır. Buna göre AFF değerinin 0.0244 olması çok şekilsiz üçgen bir parseli tanımlarken, AFF değerinin 0.0625 olması kare bir parseli tanımlamaktadır. Şekilden de görüldüğü gibi AT sonrasında parseller çoğunlukla dikdörtgen şekillere sahiptir.

Parsellerin, arazi toplulaştırmadan önceki ve sonraki şekillerinin Şekil Faktörü İndeksi (FORM)'ne göre değişimleri Şekil 5'tedir. Parsel şekillerini değerlendiren FORM 0 ile 1 arasında değerler almaktadır. AT öncesinde minimum, ortalama ve maksimum FORM indeks değerleri $0.0054,0.5334$ ve 0.9251 olarak hesaplanmıştır. AT sonrası ise FORM indeks değerleri minimum, ortalama ve maksimum $0.0584,0.5848$ ve 0.8075 olarak hesaplanmıştır. Jiao ve Liu (2012)'nun Çin'de yaptıkları çalışmada Şekil Faktörünü şahıs parsellerinde minimum 0.27 , ortalama 0.58 , maksimum 0,81 olarak hesaplamışlardır. AT sonrasında parsel şekillerinde şekil faktörü indeksine göre de iyileşme olduğu görülmektedir.

Arazi Toplulaştırma öncesi ve sonrasında parsellerin Kare Piksel Ölçeği (SqP) indeks değerlerinin değişimi Şekil 6' da verilmiştir. SqP değerleri AT öncesinde minimum -1.0400 , ortalama -0.7819 ve maksimum -0.0834 , AT sonrasinda ise minumum -1.0131, ortalama 0.8478 ve maksimum -0.2722 bulunmuştur. 
Değirmenci vd. (2019), çalışmalarında AT öncesinde Kare Piksel ölçeği (SqP) değerlerini minimum -1.02 , ortalama -0.81 ve maksimum -
0.34 hesaplamışlardır. Bu değer de (1- $\left.\frac{2}{\sqrt{\pi}}\right)$ ile 1 değerleri arasında değişmektedir.

\section{AT ÖNCESI}

Alan Şekil Faktörü (AFF)

$0.000437-0.015421$

$0.015422-0.032820$

$0.032821-0.044195$

$0.044196-0.055302$

$0.055303-0.093792$

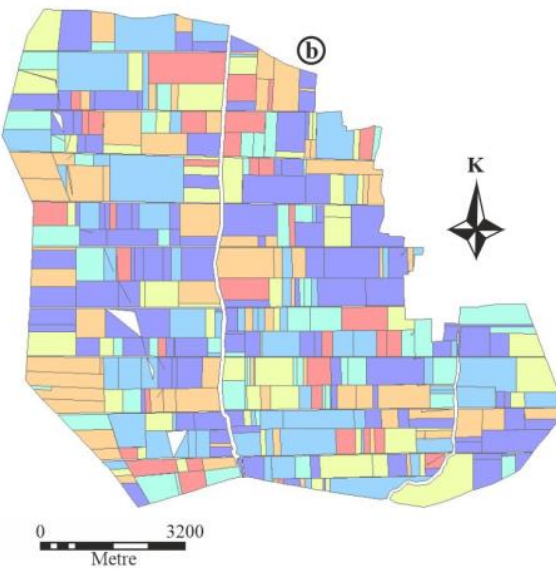

AT SONRASI

Alan Şekil Faktörü (AFF)

$0.004648-0.023683$

$0.023684-0.035770$

$0.035771 \cdot 0.045487$

$0.045488-0.052725$

$0.052726-0.058443$

Şekil 4. Alan Şekil Faktörü İndeksi (AFF) haritası. (a) Arazi toplulaştırma öncesi. (b) Arazi toplulaştırma sonras1
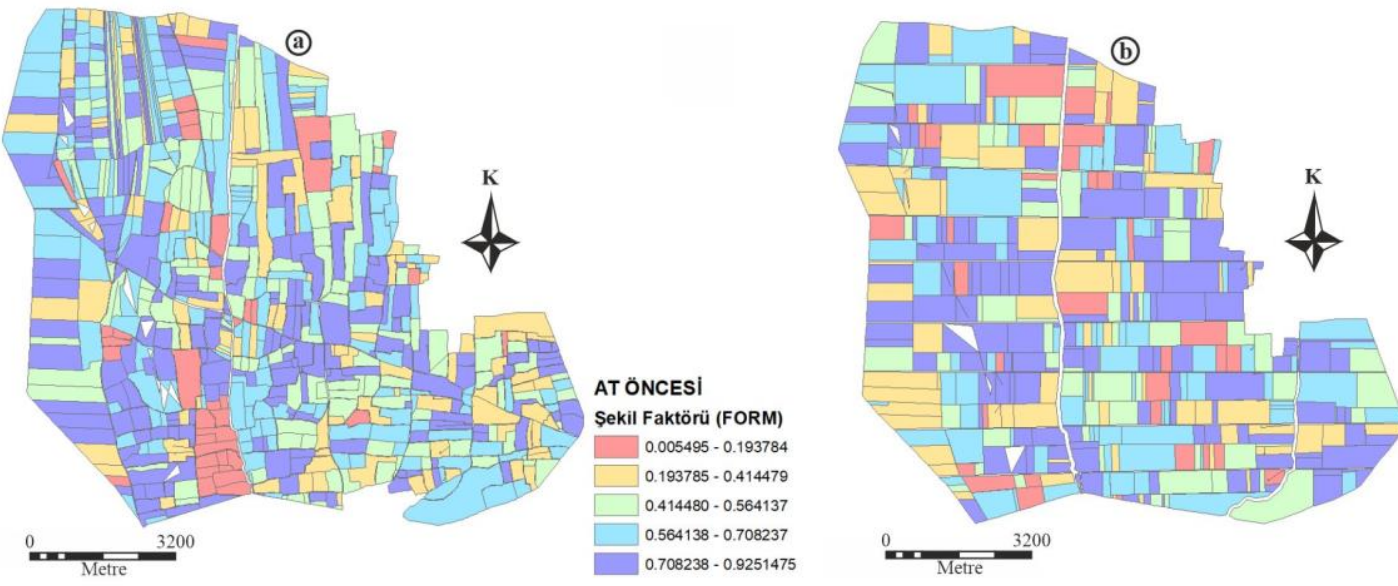

AT SONRAS

Şekil Faktörü (FORM)

$0.058403-0.297611$

$0.297612-0.449493$

$0.449494-0.591885$

$0.591886-0.710882$

$0.710883-0.807496$

Şekil 5. Şekil Faktörü İndeksi (FORM) haritası. (a) Arazi toplulaştırma öncesi. (b) Arazi toplulaştırma sonrası
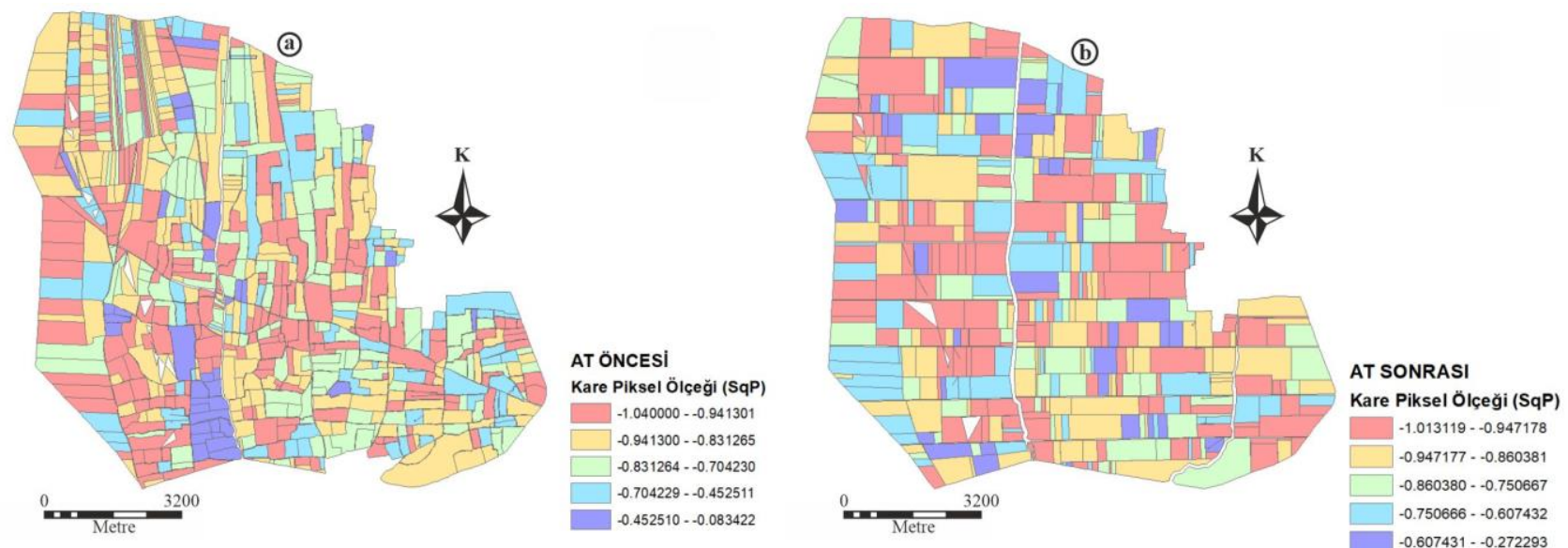

Şekil 6. Kare Piksel Ölçeği İndeksi (SqP) haritası. (a) Arazi toplulaştırma öncesi. (b) Arazi toplulaştırma sonras1 
Arazi Toplulaştırma öncesi ve sonrası parsellerin Alan Çevre Oranı indeks (APR) değerlerinin değişimi Şekil 7'de verilmiştir. AT öncesi APR indeksinin minimum, ortalama ve maksimum değerleri 1.9994, 6.5530 ve 47.8209, AT sonras1 ise $3.9448,4.9320$ ve 14.6686 olarak bulunmuştur. AT öncesinde iki parselde APR değeri çok büyük

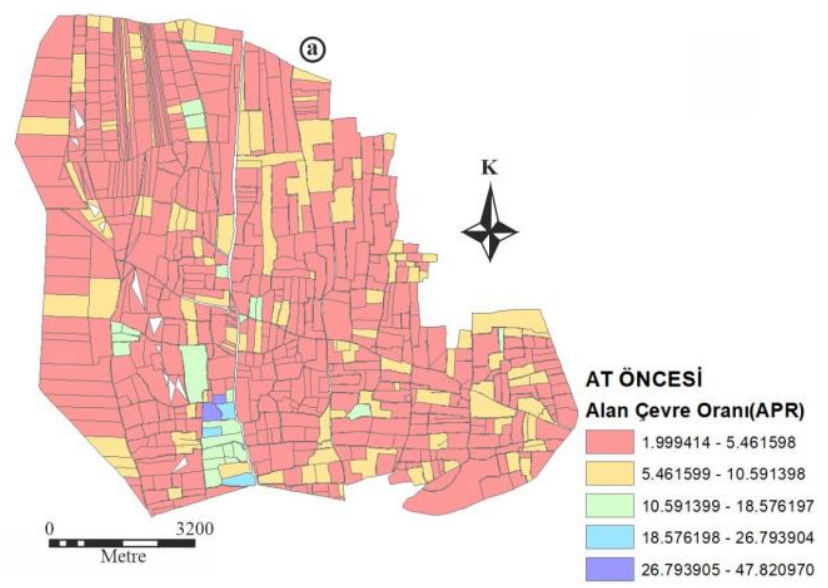

çıkmıştır. AT sonrasında şekilde de görüldüğü gibi bu değerlerde iyileşme olduğu görülmektedir. Değirmenci vd. (2019) tarafindan yapılan çalışmada APR değerini AT öncesi minimum 3.93, maksimum 11.50 ve ortalama 5.04, AT sonrasinda sirasiyla $3,92, \quad 11.66$ ve 5,14 olarak hesaplamışladır.

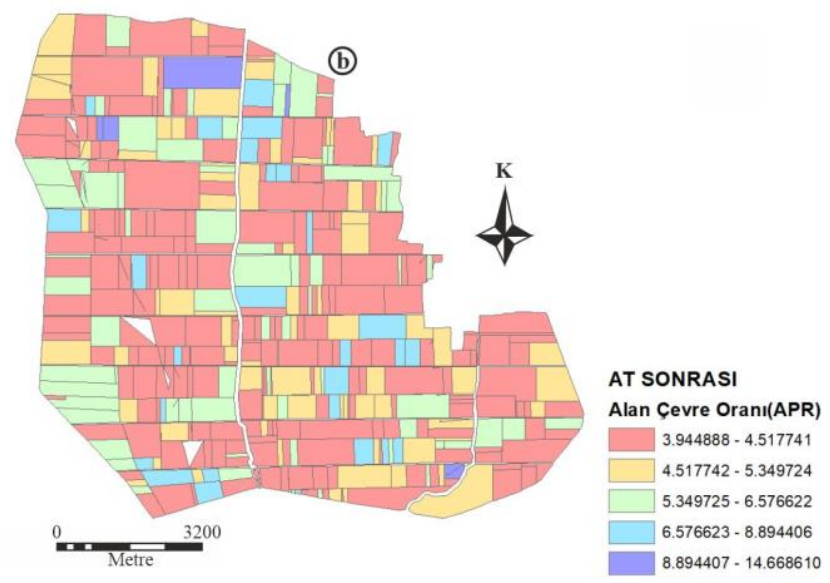

Şekil 7. Alan Çevre Oranı İndeksi (APR) haritası. (a) Arazi toplulaştırma öncesi. (b) Arazi toplulaştırma sonras1

Arazi Toplulaştırma öncesi ve sonrası Compactness İndeks (Icmp) değerlerinin değişimini gösteren harita Şekil 8'de verilmiştir. Çalışma alanında Icmp değerleri AT öncesi 0.0054 ile 0.6202 arasindayken, AT sonrasinda 0.0584 ile 0.8074 değerleri arasındadır. Toplulaştırma sonrasinda ortalama Icmp 0.5334 'ten 0.5848 'e

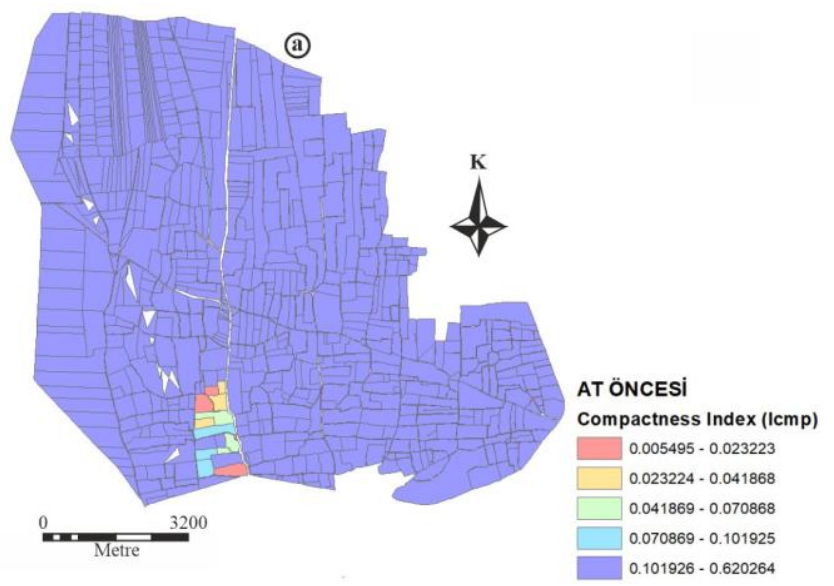

çıkmıştır. Geısse ve Hudecová (2019) yaptıkları çalışmada AT öncesinde 0.146 ile 0.217 , AT sonrasında ise 0.243 ile 0.781 değerleri arasında değişmektedir. Compactness indeks değeri $0-1$ arasında değişmektedir. AT sonrasında Compactness indeks değeri 1'e yaklaşmıştır bu da parsel şekillerinin iyileştiğini göstermektedir.

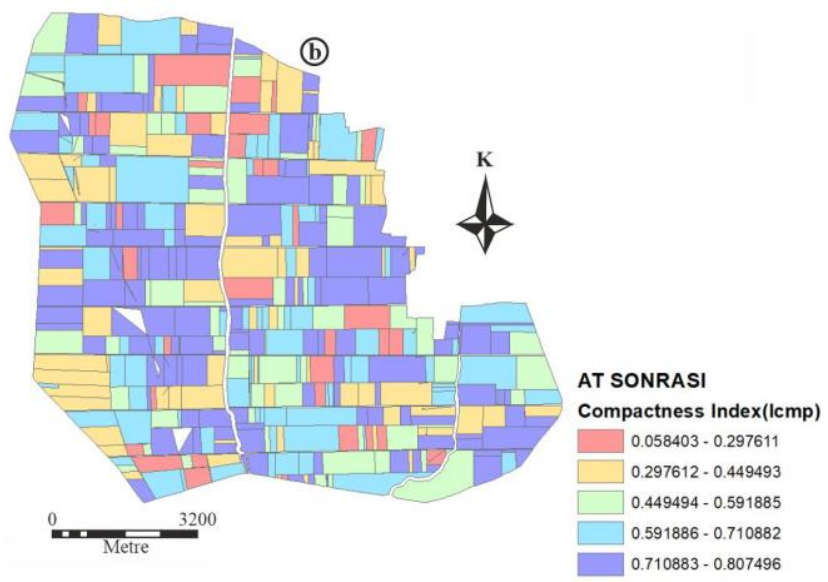

Şekil 8. Compactness İndeksi (Icmp) haritası. (a) Arazi toplulaştırma öncesi. (b) Arazi toplulaştırma sonrası

\section{Sonuçlar}

Arazi toplulaştırma projelerinin sağladığ yararlardan birisi de parsel şekillerinin iyileştirilmesidir. Parsellerin düzgün şekillere sahip olması tarımsal mekanizasyonun uygulanabilmesi açısından önemlidir. Çünkü tarımsal gelir ile parsel şekilleri arasında yakın bir ilişki vardır. Parsellerin şekilleri tarımsal sulamayı ve mekanizasyonu doğrudan etkilemektedir. $\mathrm{Bu}$ durum, arazi sahiplerine üretim sırasında kolaylık sağlamada ve gelirlerini arttırmaktadır. Bundan dolay1 parsellerin tarımsal mekanizasyona uygun oluşması ve toplulaştırma sonrası bunun 
araştırılması önemlidir. Bu araştırmada Konya, Çumra, Abditolu mahallesinde yapılan arazi toplulaştırma projesi sonrasında parsel şekillerinin nicel olarak incelenmesi amaçlanmıştır. Bunun için Arazi toplulaştırma projesi uygulanmadan önce ve toplulaştırma projesi yapıldıktan sonra parsel şekillerinin değişimi Fraktal Büyüklük İndeksi (FD), Alan Şekil Faktörü (AFF), Şekil Faktörü (FORM), Şekil İndeksi (SI), Kare Piksel Ölçeği (SqP), Alan Çevre Oranı (APR) ve Compactness İndeksleri (Icmp) kullanılarak belirlenmiştir. Ayrıca, elde edilen verilerde Coğrafi Bilgi Sistemi yardımıyla haritalandırılmıştır.

Genel olarak toplulaştırma sonrasında şekilsiz parsel sayıs1 azalarak, parseller tarımsal mekanizasyonun uygulanabileceği dikdörtgen şekillere dönüşmüştür. Çalışma sonucunda, bu uygulama alanı için Fraktal Büyüklük İndeksi (FD), Şekil Faktörü (FORM), Şekil İndeksi (SI) ve Compactness indekslerine (Icmp) göre parsel şekillerinde iyileşme olduğu görülmektedir ve bu çalışma için bu indekslerin kullanılması önerilir. Fakat çalışmada farklı geometrik şekillere sahip parsellerin aynı indeks değerlerine sahip olabileceği tespit edilmiştir. Ayrıca Alan çevre oranı (APR) ve Kare Piksel Ölçeği (SqP) indeksleri parsel şekil değişiminin analizinde diğer indeksler kadar başarılı sonuçlar verememiştir.

İşletmelere ait parsellerin şekillerini değerlendirmek amacıyla geliştirilmiş olan bu indeksler, parsel şekillerinin düzgün geometrik şekillere ne kadar yakın olduğunu büyük oranda ölçebilen parametrelerdir. Ancak, parsel şekilleri düzgün geometrik şekiller olsa bile parsellerdeki kırık nokta sayılarının fazla olması tarım makinelerinin arazide rahat bir şekilde kullanımını engellemekte ve bu durumda arazide ekilemeyen alanlar oluşmaktadır. Bu nedenle parsel şekillerinin değerlendirilmesinde kullanılabilecek yeni indekslerin geliştirilmesinde bu kırık nokta sayılarının da dikkate alınması daha olumlu sonuçlar verecektir.

\section{Kaynaklar}

Akkaya Aslan, T., Gündoğdu, K. and Arici, I. (2007). Some metric indices for the assessment of land consolidation projects. Pakistan Journal of Biological Sciences, 10(9), 1390-1397.

Arslan, F., Değirmenci, H., Tonçer, R. ve Yoğun, E. (2017). Niğde Misli Ovası Tırhan Köyü arazi toplulaştırma projesinin değerlendirilmesi. 2. Biyosistem Mühendisliği Kongresi, Tokat.

Bayram, R. ve Değirmenci, H. (2018). Arazi toplulaştırma projelerinde parsel şekillerinin analizi: Niğgde Misli Ovası 2. kısım Yıldıztepe örneği. KSÜ Tarım ve Doğa Dergisi, 21(4), 500510.

Boonchom, W., Piewthongngam, K., Polpinit, P. and Chatavithee, P. (2017). Land consolidation of small-scale farms in preparation for a cane harvester. Computer and Electronic in Agriculture. 142, 59-69.

Cebeci, Ö. (2019). Burdur-Yeşilova-Sazak Köyü arazi toplulaştırma projesinin metrik indeksler kullanılarak değerlendirilmesi. Yüksek Lisans Tezi, Isparta Uygulamalı Bilimler Üniversitesi Lisansüstü Eğitim Enstitüsü. Isparta.

Değirmenci, H., Arslan, F. ve Keten, M. (2019). Arazi toplulaştırma projelerinde parsel şekillerinin değişimi: Şanlıurfa Bozca Köyü örneği. Türk Tarım ve Doğa Bilimleri Dergisi, 6(3), 557-565.

Demetriou, D., See, L. and Stillwell, J. (2013). A parcel shape index for use in land consolidation planning. Transactions in GIS, 17(6), 861-882.

Ertunç, E. (2020). Analysis of the effect of land consolidation projects in terms of land fragmentation and parcel shapes: the case of Konya, Turkey, Arabian Journal of Geosciences, 13(10).

FAO (2003). The design of land consolidation pilot projects in Central and Eastern Europe. FAO, Rome.

Frohn, R.C. (1998). Remote sensing for landscape ecology: new metric indicators for the monitoring, modeling, and assessment of ecosystems. Lewis Publishers, Boca Raton, FL.

Gasiorowski, J. and Bielecka, E. (2014). Land fragmentation analysis using morphometric parameters. The 9th Conference Environmental Engineering, 22-23 May 2014, Vilnius, Lithuania, 1-7.

Geisse, R. and Hudecová, L. (2019). Quantification of changes in the shape and dimensions of parcels in land consolidation. Slovak Journal of Civil Engineering, 27(1), 39-44.

Gonzalez, X.P., Alvarez, C.J. and Crecente, R. (2004). Evaluation of land distributions with joint regard to plot size and shape. Agricultural Systems, 82, 31-43.

Husár, K. (2000). Tvar areálov na príklade krajinnej pokrývky Slovenska (Fillings and planary contents of areas). Kartografické listy, 8, 91-98.

Jiang, G., Zhang, R., Ma, W., Zhou, D., Wang, X. and He, X. (2017). Cultivated land productivity potential improvement in land consolidation 
schemes in Shenyang, China: assessment and policy implications. Land Use Policy, 68, 80-88.

Jurgenson, E. (2016). Land reform, land fragmentation and perspectives for future land consolidation in Estonia. Land Use Policy, 57, 34-43.

Kirmikil, M. and Arici, I. (2013). The Role of land consolidation in the development of rural areas in irrigation areas. Journal of Food. Agriculture \& Environment, 11(2), 1150-1155.

Li, Y., Wu, W. and Liu, Y. (2018). Land consolidation for rural sustainability in China: practical reflections and policy implications. Land Use Policy, 74, 137-141.

Libecap, G.D. and Lueck, D. (2011). The demarcation of land and the role of coordinating institutions. The Journal of Political Economy, 119(3), 426467.

McGarical, K. and Marks, B.J. (1995). FRAGSTATS: spatial pattern analysis program for quantifying landscape structure. Washington, D.C., U.S. Department of Agriculture, Forest Service, General Technical Report No PNW-GTR-351.

Munnangi, A.K., Lohani, B. and Misra, S.C. (2019). A review of land consolidation in the state of Uttar Pradesh, India: Qualitative approach. Land Use Policy, https://doi.org/10.1016/j.landusepol.2019.10430 9.
Oksanen, T. (2013). Shape-describing indices for agricultural field plots and their relationship to operational efficiency. Computers and Electronics in Agriculture, 98, 252-259.

Pašakarnis, G. and Maliene, V. (2010). Towards sustainable rural development in Central and Eastern Europe: Applying land consolidation. Land Use Policy, 27(2), 545-549.

Russ, J.C. (2002). The Image Processing Handbook. Fourth ed. CRC Press, Boca Raton, FL.

Song, W. and Pijanowski, B.C. (2014). The effects of China's cultivated land balance program on potential land productivity at a national scale. Applied Geography. 46, 158-170.

Wu, Z., Liu, M. and Davis, J. (2005). Land consolidation and productivity in Chinese household crop production. China Economic Review. 16 (1), 2849.

Zhou, Y., Guo, L. and Liu, Y. (2019). Land consolidation boosting poverty alleviation in China: theory and practice. Land Use Policy, 82, 339-348.

Zhou, Y., Li, X. and Xu, C. (2020). Land consolidation and rural revitalization in China: Mechanisms and paths. Land Use Policy. https://doi.org/10.1016/j.landusepol.2019.10437 9 